\title{
Bill Hillier e as ruínas convexas
}

Luiz Amorim. Universidade Federal de Pernambuco, Programa de Pós-Graduação em Desenvolvimento Urbano, Recife, PE, Brasil.

Era uma terça-feira ensolarada, animada por ventos fortes que refrescavam aquela manhã de João Pessoa quando chegou a mim, por meio da sensível nota escrita por Alan Penn, a notícia do falecimento de Bill Hillier.

Ministrava, naquele exato momento, uma aula acerca do conceito de espaço tipo como havia formulado no capítulo oito de Space is the machine (Hillier, 1996) e da minha contribuição para a ampliação do conceito por meio inclusão da relação de visibilidade entre espaços como critério para notificação de tipos de espaço e sistemas espaciais (Amorim, 2013; 2015; 2018). Ali estava por convite das amigas Lucy Donegan e Cristiana Griz, responsáveis por disciplina de morfologia da arquitetura do Programa de Pós-Graduação em Arquitetura e Urbanismo da Universidade Federal da Paraíba. Lucy, mestre e doutora pelo Programa de PósGraduação em Arquitetura e Urbanismo da Universidade Federal do Rio Grande do Norte, havia sido orientada por Edja Trigueiro. Cristiana, mestre e doutora pelo Programa de Pós-Graduação em Desenvolvimento Urbano da Universidade Federal de Pernambuco, havia sido orientada por mim. Alguns dos alunos ali presentes eram nossos orientandos.

A evidente tristeza que o meu semblante revelava, transmutou-se, diria, quase de imediato, pois acabara de me ver, e ao olhar para Lucy e Cristiana e, mais uma vez, para os jovens alunos que nos cercavam, a nos ver nas Ruínas Circulares, conto magistral de Jorge Luís Borges: éramos todos forasteiros sonhados por um sonhador. Nesta circularidade temporal que a obra ficcional nos sugere, Bill nos criou e continuaremos a criar, em nossos sonhos, forasteiros que carregarão os sonhos daqueles que sonharam antes dele. A convexidade circular nos permite ver as partes que nos constituem, e das minhas, aquela que constitui meu olhar crítico sobre as coisas da arquitetura do edifício e da cidade e que se expressam em meu discurso, foram sonhadas por ele. Em mim, como naqueles que tiveram a oportunidade de serem afetados diretamente pelo seu convívio, existe a voz viva e forte de um dos mais importantes teóricos da arquitetura a emergirem no último quartel do século XX.

Afortunados somos nós por termos tido Bill Hillier como um dos nossos construtores, parafraseando outro gigante idealizador destas ruínas em que nos vemos, Frederico de Holanda (2019) ou simplesmente, Fred.

Minhas ruínas receberam seus contributos em 1993 quando chegou-me às mãos por intermédio de Claudia Loureiro, companheira neste sonho, uma cópia do clássico The social logic of space (Hillier; Hanson, 1984). Fomos imediatamente seduzidos pela proposição teórica absolutamente inovadora acerca da indissociabilidade entre espaço e sociedade. Claudia, em seus primeiros anos de doutorado cursados na Faculdade de Arquitetura e Urbanismo da Universidade de São Paulo, que viria a nos oferecer uma das mais belas peças escritas sobre o espaço escolar (Loureiro, 2000), e eu, em uma fase dedicada à reflexão sobre o ensino da arquitetura e do urbanismo - era membro da Comissão de Especialistas em Ensino de Arquitetura e Urbanismo da Secretaria de Ensino Superior do Ministério da Educação e Cultura, nos debruçamos sobre o livro e demos início à nossa primeira investigação conjunta; uma parceria que se estenderia por mais de 20 anos, até o seu prematuro falecimento em 2014.

O estudo sobre as características configuracionais da cidade do Recife ao longo do seu processo de formação e contínua expansão sobre sua planície estuarina foi nossa primeira investigação a aplicar as ideias contidas naquele livro que, naquele momento, já se fazia acompanhar de um conjunto de artigos publicados por Bill e seus colegas da Unit for Architectural Studies, alguns deles gentilmente cedidos por Frederico de Holanda, juntamente com artigos de sua autoria. Ali teve início uma amizade fraternal que se faz renovar a cada leitura das nossas produções, a cada mensagem que trocamos, a cada reencontro nos mais diversos rincões do mundo e a cada celebrada visita à casa de Sobradinho, onde escuto, em plena harmonia, os ecos dos seus maiores construtores - Evaldo Coutinho, 
Delfim Amorim e Bill Hillier, mas também os fraseados d'Holanda. Sob a lógica social do espaço, vivemos entre encontros e nunca, esquivanças.

A contribuição de Fred para nosso estudo se estendeu com o envio do programa AXIAL, em sua versão $3,{ }^{1}$ que permitiu analisar em nossos PCs os mapas axiais e convexos gerados a partir da cartografia histórica do Recife. Os resultados foram publicados em dois artigos (Loureiro; Amorim, 1994; Loureiro; Rigatti; Amorim, 1995) e na Revista Brasileira de Estudos Urbanos e Regionais (Loureiro; Amorim, 2000).

Assim deu-se a nossa aproximação - a minha e a de Claudia Loureiro, a Bill: por meio do brilhantismo do seu contributo teórico e rigor científico expressos em seus escritos. $\mathrm{O}$ nosso convívio pessoal teria início em 1994, quando começo a desenvolver meus estudos doutorais na Bartlett School of Graduate Studies, sob sua supervisão, ocupando, por assim dizer, o assento que Edja Trigueiro deixara com a conclusão da sua belíssima tese sobre influência da arquitetura doméstica britânica, observada por meio de periódicos do século XIX, nas casas de residência no Recife. Claudia chegaria no ano seguinte, para um doutorado sanduiche de um ano.

Bill recebeu-me em seu gabinete no terceiro andar da Phillips House. Duas janelas iluminavam o espaço, uma delas voltada para a esquina entre Tottenham Court Road e Torrington Place, de onde poder-se-ia ver claramente as linhas de movimento que o caminho frenético das pessoas traçava no chão, como as "snail trails" que iria desenhar nas múltiplas observações de uso e ocupação de espaços públicos que faria para o Space Syntax Laboratory, não apenas em Londres, mas em outras cidades inglesas. Ao lado desta janela, encontrava-se sua mesa de trabalho e, sobre ela, seu PowerBook invariavelmente aberto. Dali tinha-se a melhor isovista sobre o corredor duplamente carregado que dava acesso às salas de Julienne Hanson e Alan Penn e ao Space Syntax Laboratory. Neste sistema espacial do tipo $b$ foram forjadas robustas reflexões sobre espaço e sociedade.

Naquela tarde de setembro tive a primeira oportunidade de apresentar minha proposta de pesquisa - estudar a possível constituição de uma escola de arquitetura moderna no Recife, como proposto por alguns historiadores da arquitetura (Bruand, 1986), tendo como objeto de estudo as residências projetadas entre os anos de 1930 e 1970.

Buscava observar se haveria uma assinatura espacial subjacente à diversidade expressiva da forma arquitetônica, problema este alterado com o desenrolar da investigação. Ouvi suas considerações, recomendações e uma advertência: "Amorim - com o som da letra $m$ estendido como em museum, como costumava dirigir-se a mim para cativar minha total atenção às suas palavras - I do not read chapters, only theses". Em novembro de 1998 recebeu uma tese (Amorim, 1999), assim acreditei que fosse, devidamente editada, sem que tivesse lido um único capítulo.

Naquele espaço fui recebido para nossas sessões de orientação não regulares, sempre provocadas pelas necessidades próprias da pesquisa doutoral. Assim consideramos mais adequado. Estando presente cotidianamente na Philips House, sentia-me a vontade para, sempre às tardes, bater à sua porta para conversas rápidas ou mais demoradas, segundo sua disponibilidade. Tratávamos, também, da condução dos PhD Seminars, que coordenei por quase três anos, atendendo ao seu convite, após Beatriz Campos declinar da função para dedicar-se plenamente à conclusão da sua tese.

É necessário confessar que reavivar os $P h D$ Seminars não foi tarefa fácil. Muitos receavam submeter os resultados parciais das suas pesquisas às considerações críticas dos colegas, mas principalmente das arguições demolidoras de Bill, que poderiam ter início na primeira sentença pronunciada pelo apresentador e só concluir uma hora e meia depois, sem que o primeiro slide tenha sido substituído pelo segundo. Saber apresentar e argumentar era imprescindível. Um teste de prova que o próprio Bill se submetia ao apresentar suas novas ideias ao conjunto de pesquisadores que constituíam a Unit. Nenhuma ideia nova dali saia sem que fosse devidamente considerada pelos seus pares.

Em um sábado sombrio no final de dezembro de 1998, como costumam ser os dias de outono e inverno londrinos, recebo uma ligação nas primeiras horas da manhã: "Amorim, good morning. Please go to page ...". Bill estava a ler a tese. Assim transcorreu todo o final de semana: "Amorim, please go to page ..." Até que na tarde de domingo 
recebo o último telefonema:

"Congratulations, we do have a thesis!"

Sua defesa, realizada em Brasília, durante a realização do Second International Space

Syntax Symposium, transcorreu-se de forma inusitada. Foi a primeira tese da UCL a ser defendida fora dos seus limites, a primeira a ser conduzida por dois avaliadores externos à Unit - os professores Lionel March e Mario Kruger, e, salvo engano, a primeira defesa de tese de um dos seus alunos da qual participara, mas na qualidade de representante da UCL, uma exigência formal da qual não poderia se esquivar. Obrigado a não tecer quaisquer considerações sobre o trabalho em avaliação, sentia-o, afastado da mesa onde transcorria o mais prazeroso embate acadêmico do qual participei, em ânsias de participar daquela conversa. Pela primeira vez ouvi o seu silêncio e, posso dizer, era retumbante.

Estive com Bill em Santiago do Chile, na memorável edição coordenada por Margarita Green, sem saber que este seria nosso último encontro. Infelizmente, não pude participar do 9th International Space Syntax Symposium em Seul (2013) e do 10th International Space Syntax Symposium, em seu segundo retorno a Londres, quando preparava minha documentação para progressão para a categoria de professor titular da Universidade Federal de Pernambuco, onde as referências a Bill

\section{Notas}

${ }^{1} \mathrm{O}$ programa desenvolvido por Luciano Domenico Giordana, sob a coordenação de Frederico de Holanda, prestava-se como um

\section{Referências}

Amorim, L. (1999) The Sectors' Paradigm: a study of the spatial and functional nature of modernist housing in Northeast Brazil. Tese (PhD) Advanced Architectural Studies. Londres, Bartlett School of Graduate Studies, University College London.

Amorim, L. (2013) Espaço-tipo: de a $\alpha$ a d $\delta$; In: $6^{\circ}$ Projetar, 2013, Salvador. Anais do $6^{\circ}$ Projetar. Salvador, FAUFBA, s/p.

Amorim, L. (2015) Da origem dos sistemas espaciais. Projetar: projeto e percepção do ambiente. 1, 75-83.

Amorim, L. (2018) Espaços tipo: de a $\varepsilon$ a d $\tau$. In: V Encontro da Associação Nacional de Pesquisa e Pós-Graduação em Arquitetura e Urbanismo, 2018, Salvador. Anais do V Enanparq Arquitetura e Urbanismo no Brasil atual: crises, impasses $e$ desafios. Salvador, FAUFBA. v.2. pp.3162-3175 permeavam todo o memorial/tese submetido à apreciação da banca de arguição e avaliação. Teria sido uma oportunidade para discutir minhas reflexões sobre uma extensão do conceito de espaço tipo formulada em Space is the machine, como referido acima, e apresentada como parte integrante da minha tese em um dos PhD Seminars, em 1998, mas desenvolvida após a sua conclusão, por sua própria recomendação. Considerava que os argumentos e os resultados já obtidos conferiam a robustez necessária à tese.

Esperava reencontrá-lo em Lisboa, em 2017. Desta feita, foi Bill que não pode se fazer presente. Na comunicação enviada à Teresa Heitor, coordenadora do simpósio, e lida em sessão plenária, lamentava por não estar presente. Soou-me como uma despedida e assim o foi, pelo menos para mim. Relembrei os encontros efusivos que tivemos em Brasília, Atlanta, Londres, Delft, Istambul e Santiago, sempre curioso por conhecer meus últimos estudos e ouvir minhas considerações sobre os seus - acreditava, de fato, que todo avanço científico se faz pela crítica severa dos seus pares.

Tive a oportunidade de ir a Londres em novembro daquele mesmo ano, quando revi Sophia Psarra e Kayvan Karimi. Tinha a esperança de reencontrar Bill em uma das suas já raras visitas à Bartlett. Fui reencontrálo, em um sonho borgeano, naquela manhã de terça-feira, na cidade de João Pessoa.

substituto para quem não possuísse um Macintosh e não tivesse acesso ao já mitológico programa Axman, de Nick "Sheep" Dalton.

Borges, L.J. (1998) Ruínas Circulares. Em: Ficções. Obras Completas. Volume 1. Editora Globo, S.A.

Bruand, Y. (1986) Arquitetura contemporânea no Brasil. São Paulo, Perspectiva.

Holanda, F. (2019) Construtores de mim. Brasília, FRBH.

Hillier, B., HANSON, J. (1984) The social logic of space. Cambridge, Cambridge University Press.

Hillier, B. (1996) Space is the machine: a configurational theory of architecture. Cambridge, Cambridge University Press.

Loureiro, C. (2000) Classe, controle, encontro: o espaço escolar. Tese (PhD) Arquitetura e Urbanismo. Faculdade de Arquitetura e Urbanismo, Universidade de São Paulo. 
Loureiro, C.; Amorim, L. (1994) Dos Holandeses ao nosso caos, ou é dos sonhos dos homens que uma cidade se inventa In: $3^{\circ}$ Seminário de História da Cidade e do Urbanismo, 1994, São Carlos. Anais do Seminário de História da Cidade e do Urbanismo. São Carlos: Universidade de São Paulo, s/p.

Loureiro, C.; Rigatti, D.; Amorim, L. (1995) Forma e uso do espaço urbano: Porto Alegre e Recife. Pós - Revista do Programa de Pós Graduação em Arquitetura e Urbanismo da FAU/USP, 5, 17-31.
Loureiro, C.; Amorim, L. (2000) O mascate, o bispo, o juiz e os outros: sobre a gênese morfológica do Recife. Revista Brasileira de Estudos Urbanos e Regionais, n. 2 , 19-38.

Trigueiro, E. (1995) Change (and continuity) in domestic space design: a comparative study of nineteenth and early twentieth century houses in Britain and Recife, Brazil. Tese (PhD) Advanced Architectural Studies. Bartlett School of Graduate Studies, University College London, Londres. 